\title{
Diets high in fermentable protein and fibre alter tight junction protein composition with minor effects on barrier function in piglet colon
}

\author{
Jan F. Richter ${ }^{1,2_{*}^{*}}$, Robert Pieper $^{3}$, Silke S. Zakrzewski ${ }^{2}$, Dorothee Günzel ${ }^{2}$, Joerg D. Schulzke ${ }^{4}$ and \\ Andrew G. Van Kessel ${ }^{5}$ \\ ${ }^{1}$ Institute of Anatomy II, University of Jena, Teichgraben 7, 07743 Jena, Germany \\ ${ }^{2}$ Institute of Clinical Physiology, Charité - Universitätsmedizin Berlin, Berlin, Germany \\ ${ }^{3}$ Department of Veterinary Medicine, Institute of Animal Nutrition, Freie Universität Berlin, Königin-Luise-Straße 49, 14195 \\ Berlin, Germany \\ ${ }^{4}$ Division of Nutritional Medicine, Department of Gastroenterology, Charité - Universitätsmedizin Berlin, Berlin, Germany \\ ${ }^{5}$ Department of Animal and Poultry Science, University of Saskatchewan, 51 Campus Drive, Saskatoon, Saskatchewan, \\ Canada $S 7 N 5 A 8$
}

(Submitted 2 May 2013 - Final revision received 24 September 2013 - Accepted 28 September 2013 - First published online 11 November 2013)

\begin{abstract}
Protein fermentation end products may damage the colonic mucosa, which could be counteracted by dietary inclusion of fermentable carbohydrates (fCHO). Although fermentable crude protein (fCP) and fCHO are known to affect microbial ecology, their interactive effects on epithelial barrier function are unknown. In the present study, in a $2 \times 2$ factorial experiment, thirty-two weaned piglets were fed lowfCP/low-fCHO (14.5\% crude protein (CP)/14.5\% total dietary fibre (TDF)), low-fCP/high-fCHO (14.8\% CP/16.6\% TDF), high-fCP/lowfCHO (19.8\% CP/14.5\% TDF) and high-fCP/high-fCHO (20.1\% CP/18.0\% TDF) diets. After $21-23 \mathrm{~d}$, samples of proximal and distal colonic mucosae were investigated in Ussing chambers with respect to the paracellular and transcytotic passages of macromolecules and epithelial ion transport. The high-fCHO diets were found to reduce the permeability of the distal colon to the transcytotic marker horseradish peroxidase (HRP, $44 \mathrm{kDa} ; P<0.05$ ) and also reduce the paracellular permeation of $N$-hydroxysuccinimide-biotin into the submucosa ( $443 \mathrm{Da}$; $P<0.05)$, whereas that of HRP was decreased by the high-fCP diets $(P<0.01)$. Short-circuit current (active ion transport), transepithelial resistance (barrier function) and charge selectivity were largely unaffected in both the segments. However, the high-fCP diets were found to suppress the aldosterone-induced epithelial $\mathrm{Na}$ channel activity $(P<0.01)$ irrespective of fCHO inclusion. The high-fCP diets generally reduced the expression of colonic claudin- 1 , claudin- 2 and claudin-3 $(P<0.01)$, while that of claudin- 4 was increased by the high-fCHO diets $(P<0.01)$. The high-fCHO diets also altered the ratio between occludin forms $(P<0.05)$ and increased the expression of tricellulin in the proximal colon, which was not observed with high-fCP diets. In conclusion, dietary fCHO and fCP exerted few and largely independent effects on functional measurements, but altered tight junction protein composition in a compensatory way, so that colonic transport and barrier properties were only marginally affected.
\end{abstract}

Key words: Epithelial barrier: Tight junctions: Macromolecule passage: Fermentable protein: Fermentable fibre

In recent years, dietary modulation of the intestinal microbial composition and activity has been the subject of intense research efforts, as evidence has emerged that targeted modulation of colonic bacterial metabolism may lead to health effects ${ }^{(1-3)}$. Proteins and carbohydrates are two major chemical components of the diet known to affect intestinal microbial metabolism in pigs.

Dietary fermentable carbohydrates (fCHO) include diverse physico-chemical forms such as dietary fibre and resistant starch that escape digestion and absorption and serve as substrates for microbial fermentation yielding lactic acid or
SCFA such as acetic, propionic and butyric acids. SCFA are considered to be beneficial to the host intestine as they provide energy for epithelial cells, inhibiting potential pathogen growth, stimulating epithelial proliferation, facilitating tight junction formation and inhibiting inflammation and genotoxicity $^{(1,4,5)}$. Indigestible protein that reaches the large intestine together with endogenous secretions from the proximal parts of the intestine can serve as substrate for microbial fermentation and can thus be called fermentable crude protein (fCP). Microbial breakdown of proteins may yield

Abbreviations: $\mathrm{ENaC}$, epithelial sodium channel; fCHO, fermentable carbohydrates; fCP, fermentable crude protein; FITC, fluorescein isothiocyanate; HRP, horseradish peroxidase; NHS, $N$-hydroxysuccinimide.

*Corresponding author: J. F. Richter, fax +493641 938552, email jan.richter@med.uni-jena.de 
branched-chain fatty acids, ammonia, biogenic amines, hydrogen sulphide, and phenolic and indolic compounds ${ }^{(4,6-8)}$. Many of these fermentation products are considered to be toxic and believed to exert negative effects on the intestinal mucosa ${ }^{(4,9)}$ by interfering with inflammatory responses ${ }^{(10)}$ or by directly affecting tight junctions, ion transport processes $^{(11-13)}$ or their interplay ${ }^{(14)}$. These responses are known to affect intestinal barrier function and may predispose to inflammatory bowel disease ${ }^{(15-18)}$ and cancer ${ }^{(5)}$ in humans and to diarrhoea and enteric infection in pigs ${ }^{(6,19-22)}$.

Dietary inclusion of fCHO may alleviate the negative effects of protein fermentation. For example, dietary inclusion of fCHO has been shown to effectively modulate intestinal microbial metabolism to increase SCFA content ${ }^{(20,23)}$, decrease abundance of protein fermentation products ${ }^{(22)}$, and modulate susceptibility to pathogen colonisation and abundance of harmful bacteria in the gut ${ }^{(24,25)}$. However, most of the studies have focused on the luminal environment of the intestine without investigating the effects on the colonic mucosa, particularly on epithelial barrier function. Using the pig model, several studies have reported that there is no change in small intestinal ${ }^{(23,24,26)}$ or colonic morphology ${ }^{(22)}$ in response to high-protein diets. Recently, we determined the influence of fCP and fCHO on the large intestinal microbial ecology and the mucosal expression of markers of cell turnover, mucin and inflammatory cytokines ${ }^{(27)}$. We found that whereas fCHO partially reduced the formation of putatively toxic metabolites such as ammonia and amines and increased clostridial counts, activation of genes associated with immune response, such as $I L-6$ and $I L-1 \beta$ was increased with fCP irrespective of $\mathrm{fCHO}$ inclusion ${ }^{(27)}$.

The present study aimed to determine the effect of fCP and $\mathrm{fCHO}$ and their interaction on the barrier function of proximal and distal colonic mucosae in weaned piglets. We hypothesised that (1) diets high in fCP will alter the functions of colonic mucosa, particularly the barrier function of mucosal epithelium, and (2) this can be reversed by dietary inclusion of fCHO.

\section{Materials and methods}

All procedures involving animal handling and treatments were approved by the local state office of occupational health and technical safety (LaGeSo Registration no. 0249/10).

\section{Animals, diets and sampling}

A total of thirty-two weaned piglets (Euroc $\times$ Piétrain) were placed in pens balancing for body weight, litter and sex. The piglets were randomly assigned to one of four dietary treatment groups in a $2 \times 2$ factorial experiment as specified in detail by Pieper et al. ${ }^{(27)}$. Piglets in each treatment group were fed one of the four following diets: low-fCP/low-fCHO (14.5\% $\mathrm{CP} / 14.5 \%$ total dietary fibre); low-fCP/high-fCHO (14.8\% CP/ $16.6 \%$ total dietary fibre); high-fCP/low-fCHO (19.8\% $\mathrm{CP} / 14.5 \%$ total dietary fibre); high-fCP/high-fCHO (20.1\% $\mathrm{CP} / 18.0 \%$ total dietary fibre). The diets were formulated to meet or exceed the nutrient requirements of weanling piglets ${ }^{\text {(28) }}$ (Table S1, available online). To increase the flow of indigestible protein and thus fermentable protein into the hindgut, the soyabean meal was autoclaved at $124^{\circ} \mathrm{C}$ for $20 \mathrm{~min}$ for groups being fed the high-fCP diets ${ }^{(27)}$. The piglets were killed after 20-23 experimental days (48-51 d of age) for sampling of large intestinal tissue. At $20 \mathrm{~cm}$ from the caecum, an approximately $20 \mathrm{~cm}$ segment was taken to represent the proximal colon. Correspondingly, a $20 \mathrm{~cm}$ segment was prepared ending $20 \mathrm{~cm}$ before the rectum, and it represented the distal colon. Colonic segments were cut open along the mesenteric border, rinsed with cold saline and transported to the laboratory in oxygenated cold saline solution $\left(4-7^{\circ} \mathrm{C} ; 0 \cdot 9 \% \mathrm{NaCl}+1\right.$ $\mathrm{mmol} / \mathrm{C} \mathrm{CaCl}_{2}$ ). Before the experiments, mucosae were stripped of the serosa, and fractions were snap-frozen in liquid $\mathrm{N}_{2}$ and stored at $-80^{\circ} \mathrm{C}$ for subsequent analysis.

\section{Electrophysiological measurements}

The stripped mucosae were mounted into Ussing chambers with an effective area of $0.28 \mathrm{~cm}^{2}$. These were driven by an eightchannel computer-controlled voltage clamp device (Fiebig) as described previously ${ }^{(29)}$. The bath solution contained the following components: $113.6 \mathrm{~mm}-\mathrm{NaCl} ; 2.4 \mathrm{~mm}-\mathrm{Na}_{2} \mathrm{HPO}_{4}$;

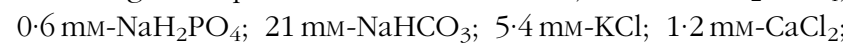
$1 \mathrm{~mm}-\mathrm{MgSO}_{4} ; \quad 10 \mathrm{~mm}-\mathrm{D}(+)$-glucose; $\quad 0.5 \mathrm{~mm}-\beta-\mathrm{OH}$-butyrate; 2.5 mm-glutamine.

Antibiotics (azlocillin (50 mg/l) and tobramycin ( $4 \mathrm{mg} / \mathrm{l})$ ) were used to prevent bacterial growth, and they had no effect on short-circuit current $\left(I_{\mathrm{SC}}\right.$ in $\left.\mu \mathrm{A} / \mathrm{cm}^{2}\right)$. The solution was gassed and mixed using a bubble lift $\left(95 \% \mathrm{O}_{2}\right.$ and $5 \% \mathrm{CO}_{2}$, $\mathrm{pH} 7$.4). The temperature was kept constant at $37^{\circ} \mathrm{C}$. Each side of the tissue samples was perfused with $5 \mathrm{ml}$ of bathing solution, and bovine serum albumin (final concentration $0.01 \%$ ) was routinely added and $I_{\mathrm{SC}}$ and transmucosal resistance $\left(R^{\mathrm{t}}\right.$ in $\Omega \mathrm{cm}^{2}$ ) were continuously recorded. The resistance of the bathing solution and electrode offsets were determined and subtracted from raw data before each experiment.

\section{Impedance spectroscopy}

One-path impedance spectroscopy was carried out as described previously ${ }^{(30)}$. The technique differentiates the epithelial $\left(R^{\text {epi }}\right)$ and subepithelial $\left(R^{\mathrm{sub}}\right)$ portions of the transmucosal wall resistance $\left(R^{t}\right)$ based on the three-parameter model of the colonic wall. In this model, the epithelium is described as an electrical equivalent circuit by a resistor and a capacitor in parallel and the subepithelium by a resistor in series. After application of forty-eight discrete frequencies of an effective sine-wave alternating current of $35 \mu \mathrm{A} / \mathrm{cm}^{2}$, ranging from $1.3 \mathrm{~Hz}$ to $65 \mathrm{kHz}$, changes in tissue voltage were detected using phase-sensitive amplifiers (1250 frequency response analyser and 1286 electrochemical interface, Solartron Schlumberger). Complex impedance values were calculated and corrected for the resistance of the bath solution and the frequency behaviour of the measuring device. Then, for each tissue sample, the impedance locus was plotted in a Nyquist diagram and a circle segment was fitted by least-squares analysis. Due to the frequency-dependent electrical characteristics of the capacitor, $R^{\mathrm{t}}$ was obtained at low frequencies, 
whereas $R^{\text {sub }}$ was obtained at high frequencies. $R^{\text {epi }}$ was obtained from $R^{\text {epi }}=R^{\mathrm{t}}-R^{\text {sub }}$. Impedance spectroscopy was carried out $1 \mathrm{~h}$ after mounting the tissue samples.

\section{Activity of the epithelial sodium channel}

Specimens of distal colonic mucosae were mounted in Ussing chambers and subsequently incubated with $3 \times 10^{-9} \mathrm{~mol} / 1$ aldosterone on both sides. The epithelial $\mathrm{Na}$ channel (ENaC)-dependent $\mathrm{Na}$ flux was determined as the drop in $I_{\mathrm{SC}} 10 \mathrm{~min}$ after addition of amiloride $\left(10^{-4} \mathrm{~mol} / \mathrm{l}\right)$ in $\mu \mathrm{A} / \mathrm{cm}^{2}$ or as the flux of monovalent cations $\left(\mu \mathrm{mol} / \mathrm{h} \text { per } \mathrm{cm}^{2}\right)^{(31)}$.

\section{Permeability to macromolecules}

Macromolecule permeability to horseradish peroxidase (HRP) and fluorescein isothiocyanate (FITC)-dextran 4000 (TdB Consultancy) from the mucosal to the serosal compartment was determined during a $2 \mathrm{~h}$ period in Ussing chambers. Briefly, $2 \mathrm{mg} / \mathrm{ml}$ of both tracer molecules were added to the mucosal compartment and serosal HRP peroxidase activity was measured using the QuantaBlu Kit (Pierce/Thermo Scientific). In serosal samples from the same flux experiments, HRP $(44 \mathrm{kDa})$ was analysed after electrophoretic separation followed by Western blotting using an antibody specific for HRP (Table 1). The transmucosal passage of HRP was further characterised by quantifying the HRP stainings of mucosal specimens (described in the 'Staining of tissues and imaging' section). FITC-dextran fluorescence was measured using a plate reader (TECAN 200M, Tecan). For HRP active enzyme and FITC-dextran, apparent permeabilities were calculated from $(\mathrm{d} Q / \mathrm{d} t) /\left(A \times C_{\mathrm{O}}\right)$, where $\mathrm{d} Q / \mathrm{d} t$ is the cumulative amount of tracer compound appearing in the receiver compartment $v$. time, $A$ is the area tissue and $C_{\mathrm{O}}$ is the initial concentration of the tracer in the donor compartment.

\section{Dilution potentials}

Following flux assays, dilution potential measurements were of changes in permeabilities to cations and anions. Dilution potentials were measured using a modified bath solution on either the apical or the basolateral side of the epithelium. In the modified bath solution, $50 \%$ of $\mathrm{NaCl}$ was iso-osmotically replaced by mannitol for the determination of $\mathrm{Na}^{+}$and $\mathrm{Cl}^{-}$permeabilities. Ion permeabilities were calculated by means of the GoldmanHodgkin-Katz equation, as described by Günzel et $a l .{ }^{(32)}$.

\section{Surface biotinylation}

After completion of macromolecular fluxes and dilution potential measurements in the Ussing chambers, Sulfo- $N$ hydroxysuccinimide (NHS)-biotin (443 Da, final concentration $5 \mathrm{mmol} / \mathrm{l}$; Thermo Scientific) was added to the mucosal compartment $\left(10 \mathrm{~min} ; 37^{\circ} \mathrm{C}\right)$ to assess permeation into the subepithelial compartment. The tissue samples were then briefly rinsed and fixed with $2 \%$ paraformaldehyde $(1 \mathrm{~h}$; room temperature) for further analysis.

\section{Staining of tissues and imaging}

Mucosal specimens from the Ussing chamber experiments were fixed with paraformaldehyde ( $2 \%$ ) for $2 \mathrm{~h}$ followed by glycine treatment $(25 \mathrm{mmol} / \mathrm{l}, 15 \mathrm{~min}$ at room temperature) and stepwise dehydration (10\% sucrose and $20 \%$ sucrose for $1 \mathrm{~h}, 4^{\circ} \mathrm{C}$ each, followed by dehydration with $30 \%$ sucrose overnight at $4^{\circ} \mathrm{C}$ ). The tissue samples were embedded in Tissue Tek (Sakura Finetek), and blocks were stored at $-80^{\circ} \mathrm{C}$. Cryosections (six per piglet and segment, $>50 \mu \mathrm{m}$ apart, $10 \mu \mathrm{m}$ ) were prepared using a Leica CM1900 cryostat (Leica Microsystems). For staining, sections were permeabilised with $0.025 \%$ Triton X-100 (10 min; room temperature). For all the subsequent washing steps and for dilution of antibodies, tissue samples were blocked in PBS containing 6\% (v/v) goat serum and 1\% BSA for $60 \mathrm{~min}$ at room temperature. Immunostaining for HRP was carried out using Cy3-anti-HRP antibodies (Table 1; $120 \mathrm{~min}$ at room temperature); and epithelial cells were contrasted using Alexa 647-anti-E-cadherin (Table 1). Labelling of biotin (for NHS-biotinylated structures) was achieved using Dy549labelled streptavidin (1:200; Dyomics), and 647-anti-E-cadherin was used for counterstaining. 4',6-diamidin-2-phenylindol (DAPI) staining (diluted 1:2500 in PBS; room temperature for $10 \mathrm{~min}$ ) was carried out shortly before mounting the sections

Table 1. Antibodies used for Western blotting and immunofluorescence

\begin{tabular}{|c|c|c|c|c|c|}
\hline Species & Protein (+label) & $\begin{array}{c}\text { Dilution } \\
\text { (IF) }\end{array}$ & $\begin{array}{c}\text { Dilution } \\
\text { (WB) }\end{array}$ & Catalogue no. & Company \\
\hline \multicolumn{6}{|c|}{ Primary antibodies } \\
\hline Mouse & E-cadherin (AlexaFluor ${ }^{\circledR} 647$ ) & $1: 200$ & - & 560062 & Becton Dickinson Pharmingen ${ }^{\mathrm{TM}}$ \\
\hline Rabbit & Claudin-1 & - & $1: 2000$ & 519000 & Invitrogen \\
\hline Rabbit & Claudin-2 & - & $1: 2000$ & 516100 & Invitrogen \\
\hline Rabbit & Claudin-3 & - & $1: 2000$ & 341700 & Invitrogen \\
\hline Mouse & Claudin-4 & - & $1: 2000$ & 329400 & Invitrogen \\
\hline Rabbit & Occludin & - & $1: 2000$ & 404700 & Invitrogen \\
\hline Rabbit & Tricellulin & - & $1: 2000$ & 700191 & Invitrogen \\
\hline Rabbit & HRP & - & $1: 5000$ & $323-005-021$ & Jackson ImmunoResearch \\
\hline Rabbit & $\mathrm{HRP}\left(\mathrm{Cy}^{\mathrm{TM}} 3\right)$ & $1: 500$ & - & $323-165-020$ & Jackson ImmunoResearch \\
\hline \multicolumn{6}{|c|}{ Secondary antibodies } \\
\hline Sheep & POD-conjugated anti-mouse & - & $1: 5000$ & 12015218001 Lumi-Light $^{\text {Plus }}$ & Roche Diagnostics $\mathrm{GmbH}$ \\
\hline Sheep & POD-conjugated anti-rabbit & - & $1: 5000$ & 12015218001 Lumi-Light $^{\text {Plus }}$ & Roche Diagnostics $\mathrm{GmbH}$ \\
\hline
\end{tabular}

IF, immunofluorescence; WB, Western blotting; HRP, horseradish peroxidase; POD, peroxidase. 
using ProTaqs MountFluor (Biocyc GmbH). Fluorescence images were obtained using a confocal laser scanning microscope (LSM 510 META, Carl Zeiss MicroImaging GmbH). Relative quantification of subepithelial HRP or NHS-biotin signals was carried out using the ImageJ software package ${ }^{(33)}$. Analysis was carried out for one representative slice (out of six described above) per segment and piglet. Briefly, images were despeckled and $5 \times 5$ mean-filtered, and Imagej's wand tool was used to encircle the subepithelial area (E-cadherinnegative area). DAPI-negative areas were generally excluded. In the remaining area, representing the subepithelial compartment, mean intensity for HRP signal (or biotin signal) was calculated from integrated density/measured area.

\section{Western blotting}

The expression of tight junction proteins was determined by Western blotting using the membrane extracts of stripped mucosal specimens. Briefly, mucosal specimens were homogenised using Ultra Turrax (IKA) and sonicated in an iced lysate buffer containing $250 \mathrm{~mm}$-sucrose, $10 \mathrm{~mm}$-triethanolamine and protease inhibitor cocktail (Complete Mini EDTA-free; Roche Diagnostics $\mathrm{GmbH}$ ). After centrifugation at $1000 \mathrm{~g}$ for $10 \mathrm{~min}$ at $4^{\circ} \mathrm{C}$, the supernatant was centrifuged at $20000 \mathrm{~g}$ for $45 \mathrm{~min}$ at $4^{\circ} \mathrm{C}$. The membrane fraction was obtained by resuspending the resulting pellet in a buffer containing $150 \mathrm{~mm}-\mathrm{NaCl}, 50 \mathrm{~mm}$-Tris-HCL (pH 7.4), 2 mm-EDTA and $1 \%$ nonyl phenoxypolyethoxylethanol by consecutive passages through $26 \mathrm{G} \times 3 / 8$ needles. Protein concentrations were determined by Pierce bicinchoninic acid assay (Thermo Scientific), and equal amounts of proteins ( $15 \mu \mathrm{g}$ of each sample) were loaded on gels, separated by PAGE and transferred onto polyscreen polyvinylidene difluoride transfer membranes (PerkinElmer). Blots were incubated with primary antibodies overnight at $4^{\circ} \mathrm{C}$ (Table 1), followed by incubation with peroxidase-conjugated secondary antibodies (Table 1). Using the Lumi-LightPLUS Western Blotting Kit (Roche Diagnostics $\mathrm{GmbH}$ ), chemiluminescence signals were analysed using a FX-7 imaging system (Vilber Lourmat Deutschland $\mathrm{GmbH}$ ) and the AIDA software (Raytest) or Image ${ }^{(33)}$. For a given protein, densitometric values of single samples were normalised on the arithmetic mean of all the samples, thus representing relative abundance between the groups. HRP was analysed the same way using samples from the Ussing chamber experiments.

\section{Statistical analysis}

The results are given as means with their standard errors. Data were analysed using generalised linear model procedures in Statistical Package for the Social Sciences (version 18.0, SPSS, Inc.) with fCHO and fCP and their interaction as sources of variation. Values identified using Grubbs' test for outliers were excluded from the analysis. Differences at $P<0.05$ were considered significant, and $P$ values less than $0 \cdot 1$ were identified as trends. One-way ANOVA with post hoc test for group comparison (Tukey's honestly significant difference) was only carried out when a significant interaction of fCHO and fCP was observed. Otherwise, only the main effects of the two factors were analysed. Pearson's correlation coefficient $(r)$ was used as a measure of linear association between two variables.

\section{Results}

All the piglets remained healthy throughout the study. Data on nutrient digestibility, performance, faecal scores, large intestinal microbial ecology, mucosal oxidative stress measurements and gene expression have been published recently ${ }^{(27)}$.

Table 2. Passage of markers of the paracellular (N-hydroxysuccinimide (NHS)-biotin and FITC-dextran 4000) and transcytotic (HRP, horseradish peroxidase) pathways

(Mean values with their standard errors, $n 6-8$ per group)

\begin{tabular}{|c|c|c|c|c|c|c|c|c|c|c|c|}
\hline & \multicolumn{4}{|c|}{ Low fCP } & \multicolumn{4}{|c|}{ High fCP } & & & \\
\hline & \multicolumn{2}{|c|}{ Low fCHO } & \multicolumn{2}{|c|}{ High fCHO } & \multicolumn{2}{|c|}{ Low fCHO } & \multicolumn{2}{|c|}{ High fCHO } & \multicolumn{3}{|c|}{$P^{*}$} \\
\hline & Mean & SE & Mean & SE & Mean & SE & Mean & SE & $\mathrm{fCHO}$ & $\mathrm{fCP}$ & $\mathrm{fCHO} \times f C P$ \\
\hline \multicolumn{12}{|l|}{ Proximal colon } \\
\hline $\mathrm{P}^{\mathrm{FD} 4}\left(10^{-9} \mathrm{~cm} / \mathrm{s}\right)$ & $130 \cdot 0$ & $15 \cdot 5$ & $125 \cdot 0$ & $22 \cdot 3$ & 144.0 & $15 \cdot 5$ & $246 \cdot 0$ & $90 \cdot 1$ & 0.219 & 0.088 & 0.178 \\
\hline $\mathrm{P}^{\mathrm{HRP} / \mathrm{enzyme}}\left(10^{-9} \mathrm{~cm} / \mathrm{s}\right)$ & $18 \cdot 3$ & $3 \cdot 17$ & $20 \cdot 3$ & 11.7 & 30.9 & $13 \cdot 8$ & $19 \cdot 8$ & $7 \cdot 13$ & 0.629 & 0.522 & 0.489 \\
\hline Serosal HRP ${ }^{\mathrm{IF}}$ (ALU) & 1.80 & 0.35 & $2 \cdot 68$ & 0.79 & 4.37 & 1.77 & 1.97 & 0.42 & 0.455 & 0.361 & 0.108 \\
\hline Serosal HRPWB & 1.31 & 0.21 & 0.91 & 0.19 & 1.09 & 0.26 & 0.69 & 0.28 & 0.125 & 0.385 & 0.997 \\
\hline Serosal NHS-biotin (ALU) & 4.90 & $1 \cdot 83$ & $6 \cdot 79$ & $2 \cdot 92$ & 13.5 & 4.85 & $10 \cdot 2$ & $4 \cdot 23$ & 0.842 & 0.088 & 0.461 \\
\hline \multicolumn{12}{|l|}{ Distal colon } \\
\hline $\mathrm{P}^{\mathrm{FD} 4}\left(10^{-9} \mathrm{~cm} / \mathrm{s}\right)$ & $161 \cdot 0$ & $25 \cdot 2$ & $179 \cdot 0$ & $27 \cdot 8$ & $218 \cdot 0$ & $23 \cdot 0$ & $154 \cdot 0$ & $22 \cdot 0$ & 0.308 & 0.470 & 0.074 \\
\hline $\mathrm{P}^{\text {HRP/enzyme }}\left(10^{-9} \mathrm{~cm} / \mathrm{s}\right)$ & $17 \cdot 4$ & 3.87 & 9.94 & $2 \cdot 01$ & $22 \cdot 7$ & $6 \cdot 21$ & 11.4 & 3.59 & 0.021 & 0.401 & 0.633 \\
\hline Serosal HRP IF (ALU) & 6.41 & 1.59 & $6 \cdot 12$ & 1.91 & 3.57 & 1.00 & 1.83 & 0.42 & 0.668 & 0.002 & 0.838 \\
\hline Serosal HRPWB & 0.89 & 0.27 & 1.04 & 0.20 & $1 \cdot 16$ & 0.17 & 0.89 & 0.14 & 0.742 & 0.741 & 0.249 \\
\hline Serosal NHS-biotin (ALU) & $16 \cdot 4$ & 8.00 & $4 \cdot 18$ & 0.71 & $15 \cdot 5$ & $6 \cdot 78$ & $12 \cdot 6$ & 7.06 & 0.038 & 0.952 & 0.825 \\
\hline
\end{tabular}

$\mathrm{fCP}$, fermentable crude protein; $\mathrm{fCHO}$, fermentable carbohydrates; $\mathrm{P}^{\mathrm{FD} 4}$, permeability to fluorescein isothiocyanate-dextran 4000; $\mathrm{P}^{\mathrm{HRP} / \mathrm{enzyme}}$, permeability to $\mathrm{HRP}$ measured as enzymatic activity in the serosal compartment; serosal HRP ${ }^{\mathrm{IF}}$, immunofluorescence signal of HRP in the submucosa; ALU, arbitrary light units; serosal HRPWB, relative amount of HRP protein in Ussing chamber serosal compartment measured by Western blotting; serosal NHS-biotin, fluorescence signal of biotin in the submucosa.

* Probability of the main effects of $\mathrm{fCHO}$ and $\mathrm{fCP}$ as well as their interaction ( $\mathrm{fCHO} \times \mathrm{fCP}$ ). 


\section{Barrier function to macromolecules was largely unaffected}

The mucosal-to-serosal permeation of macromolecules of different sizes, namely NHS-biotin (443 Da), FITC-dextran ( $4 \mathrm{kDa}$ ) and HRP ( $44 \mathrm{kDa}$ ), is summarised in Table 2 . The permeability of the distal colon to HRP was lower $(P<0.05)$ in the high-fCHO diet-fed piglets when measured as an active enzyme, but it was found to be unaffected by treatment when immunoreactive HRP protein was analysed by Western blotting. The abundance of HRP within the colonic mucosa was measured as immunoreactivity in the subepithelial compartment, and it was found to be lower $(P<0.01)$ in the distal colon of the high-fCP diet-fed piglets. The permeability of the proximal colon to FITC-dextran tended to be higher $(P=0.09)$ in the high-fCP diet-fed groups, whereas in the distal colon, a trend $(P=0.07)$ towards a fCP $\times$ fCHO interaction was observed, indicating that the high permeabilities observed with the high-fCP/low-fCHO diet were decreased by the inclusion of high $\mathrm{fCHO}$. The permeation of NHSbiotin tended to be increased also in the proximal colon of the high-fCP diet-fed groups $(P=0 \cdot 088)$, and it was reduced in the distal colon of the high-fCHO diet-fed groups $(P<0.05)$.

\section{Barrier function to inorganic ions was unaffected by diets}

The basal short-circuit current $\left(I_{\mathrm{SC}}\right)$ of colonic mucosae was not altered by the different diets (Table 3 ). $R^{\mathrm{t}}$ was unaffected in the proximal colon, but it tended to be higher in the distal colon of the high-fCP diet-fed piglets $(P=0 \cdot 06)$. The contributions of $R^{\text {epi }}$ and $R^{\text {sub }}$ to $R^{\mathrm{t}}$ also did not differ, and only a tendency for an interaction was observed for $R^{\text {epi }}$ in the distal colon $(P=0.09)$. Dilution potentials for $\mathrm{NaCl}$ were measured to detect changes in charge selectivity of tight junctions. The ratio of permeability to Na:permeability to chloride $\left(\mathrm{P}^{\mathrm{Na}} / \mathrm{P}^{\mathrm{Cl}}\right)$ tended to be decreased in high-fCP groups $(P=0.09)$ in the proximal colon, but it was not altered in the distal colon.

\section{Epithelial sodium channel activity was reduced in the high-fermentable crude protein diet-fed groups}

ENaC activity after ex vivo stimulation with nanomolar aldosterone was measured in distal colonic mucosae. The high-fCP diets suppressed inducible ENaC activity by approximately $40 \%(P<0 \cdot 01$; Table 3$)$, whereas the inclusion of fCHO had no effect.

\section{High-fermentable crude protein diets altered tight junction protein expression}

The high-fCP diets decreased $(P<0.05)$ the expression of all claudins in the proximal and distal colons, except that of claudin- 4 , which was unaffected in the proximal colon. The expression of claudin-2 was most affected, demonstrating approximately $68 \%$ reduction in the proximal colon (Table 4). Indeed, there was a tendency towards decreased $\mathrm{P}^{\mathrm{Na}} / \mathrm{P}^{\mathrm{Cl}}$ in the high-fCP diet-fed groups $(P=0 \cdot 09)$, which is

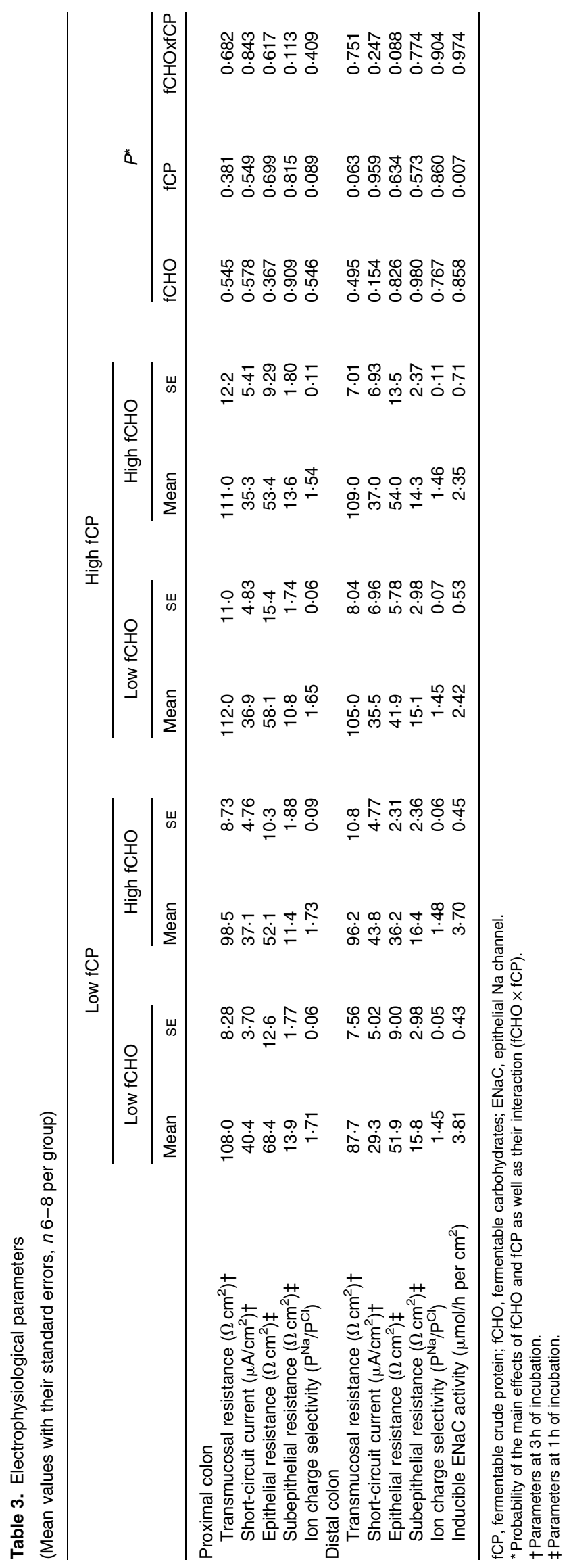


consistent with a claudin-2-mediated selectivity preference of cations over anions.

The effect of feeding fCHO was less consistent than that of feeding fCP; however, the high-fCHO diets also decreased $(P<0.01)$ the expression of claudin- 2 in the distal colon. In the proximal colon, a significant $(P<0 \cdot 01) \mathrm{fCP} \times \mathrm{fCHO}$ interaction was observed, indicating a reduction of the expression of claudin-1 by fCHO diets when fCP content was low, but not when it was high. In contrast to the fCP diets, the high-fCHO diets increased $(P<0.05)$ the expression of claudin- 4 in both the proximal and distal colons. The expression of both claudin-3 $(P=0.07)$ and claudin-4 $(P=0.08)$ in the proximal colon exhibited a trend towards a significant interaction where the high-fCHO diets appeared to increase the expression only when fCP content was low. Similarly, the expression of tricellulin in the proximal colon was markedly increased by the high-fCHO diets in a low-fCP background $(P<0 \cdot 01)$, but it remained unaltered by fCHO diets with the inclusion of high fCP ( $\mathrm{fCP} \times \mathrm{fCHO} ; P<0.05)$.

The abundance of the tight junction protein occludin was examined by analysing the prominent Western blot bands present at higher molecular weights $(59,65$ and $69 \mathrm{kDa})$ and at a low molecular weight (approximately $32 \mathrm{kDa}$; Table 5 and Supplementary Fig. 1 (available online)). While total occludin expression was unaffected, analysis of the protein abundance of occludin forms indicated significant $(P<0.05)$ interactive effects. In the proximal and distal colons, the levels of the $69 \mathrm{kDa}$ high molecular weight occludin were increased by the high-fCHO diets when fCP content was low, but not when it was high. A similar pattern was observed for the $59 \mathrm{kDa}$ high molecular weight occludin in the distal colon. Interestingly, for the $32 \mathrm{kDa}$ low molecular weight occludin, protein abundance was lowest in the high-fCP/low-fCHO diet-fed group.

\section{Discussion}

In the present study, the hypothesis that (1) diets high in fCP will alter the functions of colonic mucosa, particularly the barrier function of mucosal epithelium, and (2) this can be reversed by the inclusion of $\mathrm{fCHO}$ was investigated. We found that barrier function to macromolecules was only marginally altered and electrophysiological measurements of epithelial function, short-circuit current and transmucosal resistance were unaffected by the diets. At the same time, colonic epithelial cells reacted strongly to the imposed alteration of luminal milieu as demonstrated by (1) the decreased capacity of ENaC-mediated $\mathrm{Na}$ absorption (and probably the coupled water absorption) and (2) the markedly altered expression of tight junction proteins.

A companion study on the same animals demonstrated that the luminal microbial and metabolic milieu was profoundly altered by $\mathrm{fCHO} / \mathrm{fCP}$ variation ${ }^{(27)}$, but an overt phenotype with regard to health and performance measurements of pigs was absent. Nevertheless, a host response was clearly observed: the mucosal response to high-fCP diets included changes in the mucosal cytokine mRNA abundance profile: up-regulation of the expression of putative pro-inflammatory cytokines (such as $I L-6$ and $I L-1 \beta)$ as well as anti-inflammatory cytokines (IL-1O and transforming growth factor- $\beta)^{(27)}$ in the absence of overt inflammation.

\section{Barrier function to macromolecules}

The passage of macromolecules was studied with tracer molecules spanning three orders of magnitude in molecular weight (approximately 400-40000 Da), since permeability to bigger solutes is not necessarily predictable by transepithelial resistance $^{(34)}$, particularly where the transcellular passage route plays a role. While the passage of FITC-dextran and NHS-biotin is considered to occur via the paracellular epithelial

Table 4. Expression of tight junction proteins as determined by Western blotting*

(Mean values with their standard errors, $n$ 7-8 per group)

\begin{tabular}{|c|c|c|c|c|c|c|c|c|c|c|c|}
\hline & \multicolumn{4}{|c|}{ Low fCP } & \multicolumn{4}{|c|}{ High fCP } & & & \\
\hline & \multicolumn{2}{|c|}{ Low fCHO } & \multicolumn{2}{|c|}{ High fCHO } & \multicolumn{2}{|c|}{ Low fCHO } & \multicolumn{2}{|c|}{ High fCHO } & \multicolumn{3}{|c|}{$P+$} \\
\hline & Mean & SE & Mean & $\mathrm{SE}$ & Mean & SE & Mean & SE & $\mathrm{fCHO}$ & $\mathrm{fCP}$ & $\mathrm{fCHO} \times f C P$ \\
\hline \multicolumn{12}{|c|}{ Proximal colon } \\
\hline Claudin-1 & $1 \cdot 12$ & 0.07 & 1.25 & 0.05 & 0.80 & 0.09 & 0.80 & 0.04 & 0.302 & $<0.001$ & 0.287 \\
\hline Claudin-2 & $1 \cdot 27$ & 0.31 & $1 \cdot 71$ & 0.20 & 0.54 & 0.15 & 0.42 & 0.05 & 0.407 & $<0.001$ & 0.143 \\
\hline Claudin-3 & 1.04 & $0 \cdot 10$ & $1 \cdot 24$ & 0.05 & 0.88 & 0.08 & 0.82 & 0.07 & 0.359 & $<0.001$ & 0.066 \\
\hline Claudin-4 & 0.81 & 0.14 & 1.22 & 0.06 & 0.93 & 0.04 & 1.02 & $0 \cdot 10$ & 0.007 & 0.652 & 0.080 \\
\hline Tricellulin & $0.79^{a}$ & 0.16 & $1.38^{b}$ & 0.13 & $0.82^{\mathrm{a}}$ & 0.08 & $0.88^{a}$ & 0.05 & 0.003 & 0.033 & 0.018 \\
\hline \multicolumn{12}{|l|}{ Distal colon } \\
\hline Claudin-1 & $1 \cdot 32^{\mathrm{a}}$ & 0.06 & $1.05^{\mathrm{b}}$ & 0.05 & $0.76^{c}$ & 0.05 & $0.83^{b, c, d}$ & 0.09 & 0.098 & $<0.001$ & 0.004 \\
\hline Claudin-2 & 1.37 & $0 \cdot 16$ & $1 \cdot 11$ & 0.11 & 0.91 & 0.09 & $0 \cdot 61$ & 0.03 & 0.009 & $<0.001$ & 0.860 \\
\hline Claudin-3 & 1.25 & 0.09 & $1 \cdot 12$ & 0.09 & 0.86 & 0.09 & 0.74 & 0.09 & 0.126 & $<0.001$ & 0.944 \\
\hline Claudin-4 & 1.00 & 0.08 & $1 \cdot 21$ & $0 \cdot 10$ & $0 \cdot 81$ & 0.09 & 0.97 & $0 \cdot 10$ & 0.032 & 0.014 & 0.762 \\
\hline Tricellulin & 0.97 & 0.16 & 1.07 & 0.13 & 1.06 & 0.07 & 0.90 & 0.06 & 0.785 & 0.724 & 0.210 \\
\hline
\end{tabular}

$\mathrm{fCP}$, fermentable crude protein; $\mathrm{fCHO}$, fermentable carbohydrates.

a,b,c,d Mean values within a row with unlike superscript letters were significantly different $(P<0.05)$

${ }^{*}$ Relative amount of protein.

$\dagger$ Probability of the main effects of $\mathrm{fCHO}$ and $\mathrm{fCP}$ as well as their interaction $(\mathrm{fCHO} \times \mathrm{fCP})$. 
Table 5. Expression of occludin bands as determined by Western blotting*

(Mean values with their standard errors, $n 7-8$ per group)

\begin{tabular}{|c|c|c|c|c|c|c|c|c|c|c|c|}
\hline & \multicolumn{4}{|c|}{ Low fCP } & \multicolumn{4}{|c|}{ High fCP } & & & \\
\hline & \multicolumn{2}{|c|}{ Low fCHO } & \multicolumn{2}{|c|}{ High $\mathrm{fCHO}$} & \multicolumn{2}{|c|}{ Low fCHO } & \multicolumn{2}{|c|}{ High fCHO } & \multicolumn{3}{|c|}{$P+$} \\
\hline & Mean & SE & Mean & SE & Mean & SE & Mean & SE & $\mathrm{fCHO}$ & $\mathrm{fCP}$ & $\mathrm{fCHOxfCP}$ \\
\hline \multicolumn{12}{|l|}{ Proximal colon } \\
\hline $69 \mathrm{kDa}(\mathrm{HMW})$ & 0.90 & 0.11 & 1.34 & 0.17 & 0.95 & 0.14 & 0.81 & 0.16 & 0.282 & 0.081 & 0.040 \\
\hline $65 \mathrm{kDa}(\mathrm{HMW})$ & 1.31 & 0.21 & 0.95 & 0.08 & 1.01 & 0.12 & 0.74 & 0.12 & 0.018 & 0.053 & 0.723 \\
\hline 59 kDa (HMW) & 0.75 & 0.13 & 1.37 & 0.21 & 0.82 & 0.11 & 1.03 & 0.28 & 0.025 & 0.450 & 0.269 \\
\hline 32 kDa (LMW) & $1 \cdot 24$ & 0.26 & 0.97 & 0.21 & 1.03 & 0.19 & 0.77 & 0.20 & 0.190 & 0.311 & 0.988 \\
\hline Total occludin (sum of bands) & 1.22 & 0.21 & 1.01 & 0.14 & 1.00 & 0.14 & 0.77 & 0.14 & 0.139 & 0.120 & 0.901 \\
\hline \multicolumn{12}{|l|}{ Distal colon } \\
\hline $69 \mathrm{kDa}(\mathrm{HMW})$ & $0.49^{a}$ & 0.06 & $1 \cdot 28^{b}$ & 0.16 & $1 \cdot 35^{\mathrm{b}}$ & 0.18 & $0.89^{a, b}$ & 0.13 & 0.212 & 0.064 & $<0.001$ \\
\hline 65 kDa (HMW) & 0.97 & 0.21 & 1.00 & 0.14 & 0.96 & 0.10 & 1.08 & 0.15 & 0.627 & 0.836 & 0.756 \\
\hline $59 \mathrm{kDa}(\mathrm{HMW})$ & 0.75 & $0 \cdot 10$ & $1 \cdot 16$ & 0.19 & $1 \cdot 16$ & 0.09 & 0.93 & 0.14 & 0.466 & 0.477 & 0.014 \\
\hline $32 \mathrm{kDa}(\mathrm{LMW})$ & $1 \cdot 30^{\mathrm{a}}$ & 0.19 & $1.05^{a, b}$ & 0.26 & $0.48^{\mathrm{b}}$ & 0.11 & $1 \cdot 16^{a, b}$ & 0.17 & 0.222 & 0.045 & 0.009 \\
\hline Total occludin (sum of bands) & $1 \cdot 13$ & 0.16 & 1.07 & 0.20 & 0.70 & 0.09 & $1 \cdot 11$ & 0.15 & 0.240 & 0.188 & 0.111 \\
\hline
\end{tabular}

$\mathrm{fCP}$, fermentable crude protein; $\mathrm{fCHO}$, fermentable carbohydrates; HMW, high molecular weight; LMW, low molecular weight.

a,b Mean values within a row with unlike superscript letters were significantly different $(P<0.05)$

${ }^{*}$ Relative amount of protein.

$\dagger$ Probability of the main effects of $\mathrm{fCHO}$ and $\mathrm{fCP}$ as well as their interaction $(\mathrm{fCHO} \times \mathrm{fCP}$ ).

pathway, that of HRP, frequently used as a 'fluid-phase marker' occurs via the transcellular epithelial passage pathway ${ }^{(35,36)}$. To obtain information on the processing of foreign protein cargo during passage, we additionally quantified the expression of HRP protein by Western blotting as well as HRP immunoreactivity within mucosae. The passage of macromolecules was significantly altered only in the distal colon: inclusion of high fCHO reduced the permeation of the $443 \mathrm{Da}$ tracer NHS-biotin into the submucosa and reduced the permeability to enzymatically active HRP. This effect was independent of dietary fCP content and thus unlikely to be mediated by the reduction in the levels of toxic N-containing fermentation products ${ }^{(27)}$. The only significant effect of fCP on permeability parameters was the reduced HRP immunoreactivity within the subepithelial compartment. Since no differences were observed for intact HRP protein ( $44 \mathrm{kDa}$ band), these findings point towards dietdependent handling of foreign proteins, where high fCP probably altered mucosal intracellular protein processing. A change in the paracellular passage of HRP in the high-fCP diet-fed piglets seems unlikely, since permeability to fluorescein isothiocyanate-dextran 4000 was not increased accordingly. Hence, the passage of small- to mid-sized macromolecules appeared to be increased with high-fCP dietary treatments and larger foreign proteins are likely to be processed differently.

\section{Ion selectivity}

Ion charge selectivity did not differ significantly among the treatment groups. Compared with the strong effect of claudin-2 overexpression on ion charge selectivity in cell-culture studies $^{(37)}$, a weak correlation was observed for claudin-2 $v$. $\mathrm{P}^{\mathrm{Na}} / \mathrm{P}^{\mathrm{Cl}}$ in the present study ( $r 0.41$ in the proximal colon) and $\mathrm{P}^{\mathrm{Na}} / \mathrm{P}^{\mathrm{Cl}}$ tended to be lower in the high-fCP diet-fed groups $(P=0.089)$. If claudin-2 is sufficient to confer cation selectivity on intestinal mucosa, a strong correlation of its expression and $\mathrm{P}^{\mathrm{Na}} / \mathrm{P}^{\mathrm{Cl}}$ can be expected, which was not the case in the present study. The change in ion charge selectivity is usually accompanied by an altered $R^{\text {epi }(18,37)}$, and it is assumed that the increased abundance of claudin- 2 decreases $R^{\text {epi }}$ in the intestinal mucosa also ${ }^{(1)}$. Dietary variation of fCP/ fCHO resulting in the altered expression of claudin-2 did not affect transmucosal or epithelial resistance in the present study. In contrast to cell-culture studies, this is probably compensated by the up-regulation of tightening tight junction proteins in vivo ${ }^{(38)}$.

\section{Activity of the epithelial sodium channel}

The high-fCP diets reduced $\mathrm{ENaC}$ activity, whereas the inclusion of high fCHO had no effect. ENaC activity is strongly influenced by the inflammation status of mucosae, and it was thus a candidate effector in the present study. It has repeatedly been shown that IL- $1 \beta$ regulates $\mathrm{ENaC}$ and is even sufficient to down-regulate the function of $\mathrm{ENaC}$ in ex vivo as well as in cell-culture studies ${ }^{(39,40)}$. In IL-2-deficient mice, diarrhoea occurs in the presence of inflammation, but without obvious impairment of the barrier function probably via reduced ENaC activity ${ }^{(31,39)}$, and a similar effect can be observed in ulcerative colitis patients ${ }^{(40)}$. Additionally, ENaC induction is butyrate dependent ${ }^{(12)}$ and regulated by TNF- $\alpha$ and glucocorticoids in vitro ${ }^{(41)}$. SCFA are influenced by diet and ENaC is the last resort ion regulator located in distal epithelia - thus having a strong impact on diarrhoeal status. Indeed, the high-fCP diet-fed piglets showed mild diarrhoea: the faecal score was higher in the low-fCP/low-fCHO diet-fed group (3.49 (sE $0 \cdot 6)$ ) than in the low-fCP/high-fCHO diet-fed (2.80 (SE 0.04)), high-fCP/low-fCHO diet-fed (2.53 (SE 0.05)) and high-fCP/high-fCHO diet-fed (2.79 (SE 0.05)) groups $(P<0 \cdot 01)$. The high-fCP/low-fCHO diet-fed piglets had significantly lower faecal scores than all the other groups $(P<0 \cdot 01)$ and exhibited high-fCP-dependent $I L-1 \beta$ mRNA up-regulation in the colonic mucosa ${ }^{(27)}$.

Interestingly, a cell-culture study on $\mathrm{ENaC}$ induction has reported the activating effects of butyrate and propionate, 
but not of acetate ${ }^{(13)}$. Induction of a more pronounced shift towards butyrate production in the colon might be an option to stimulate the function of ENaC in the high-fCP diet-fed piglets.

\section{Tight junction proteins}

Intestinal well-being, inflammation and tight junctions are closely linked: tight junction proteins regulate paracellular barrier properties in epithelia ${ }^{(19,42)}$, are sensitive to the mucosal cytokine profile ${ }^{(18)}$, which has been studied extensively in inflammatory bowel disease pathology ${ }^{(16,43)}$, and are sensitive to luminal milieu, e.g. SCFA ${ }^{(11,44)}$. Permeability changes are often a result of mucosal inflammation, as it is clear that proinflammatory cytokines can directly decrease epithelial barrier function ${ }^{(15,45)}$. In the present study, the high-fCP diets decreased the expression of colonic claudin-1, claudin-2, claudin- 3 and claudin-4 (only in the distal colon). The profoundly reduced expression of colonic claudin-2 in the high-fCP diet-fed animals is surprising. Claudin-2 is a pore-forming protein, sufficient to decrease $R^{\text {epi }}$ and to confer cation selectivity on the paracellular pathway ${ }^{(37)}$. In the present study, a reduction in the expression of claudin- 2 of more than $60 \%$ unexpectedly did not result in changes in electrophysiological parameters, probably because it was accompanied by a decrease of tightening tight junction proteins. Knowledge on claudin function mostly stems from overexpression and knockdown approaches of the single proteins ${ }^{(34)}$; reports on disease-specific claudin expression profiles are inconsistent and many aspects of the claudin family interplay and resulting consequences remain mysterious $^{(19,34,46)}$. To date, the up-regulation of claudin-2 expression in inflammatory bowel disease has been the only consistent observation, and hence it is considered to be an indicator of inflammation ${ }^{(16)}$. Although the observed downregulation of claudin-2 expression in the present study might indicate that $\mathrm{fCP}$ is anti-inflammatory, the mRNA abundance of pro- and anti-inflammatory cytokines does not support this conclusion. Tricellulin is expressed at tricellular junctions. It regulates the passage of mid-sized macromolecules across epithelia ${ }^{(34)}$. In contrast to high-fCP diets, inclusion of high fCHO increased its expression in a low-protein background in the proximal colon, but there was no correlation between tricellulin expression and macromolecule passage.

Occludin is believed to exert more regulatory functions. It generally occurs as several bands on Western blots ${ }^{(47)}$, presumably reflecting the functional modifications of the protein ${ }^{(47,48)}$. It is still a matter of debate what the biological consequences of these modifications are, but occludin is regarded as a sensitive indicator of tight junction changes ${ }^{(47,49,50)}$. In contrast to changes in the abundance of claudin, we observed a dietdependent change in occludin modifications (not in total occludin abundance), consistent with a more regulatory function. An interesting finding is a lower relative abundance of the $32 \mathrm{kDa}$ occludin in the distal colon of piglets fed high-fCP diets with low fCHO content. Bojarski et al. ${ }^{(51)}$ showed that apoptosis-induced processing of occludin yielded $32 \mathrm{kDa}$ fragments. The fCP-induced reduction in the abundance of $32 \mathrm{kDa}$ occludin in the present study was abrogated by co-feeding of high $\mathrm{fCHO}$, which may reflect the differential effects of fibre $v$. protein fermentation on epithelial apoptosis and thus on epithelial turnover. Most tight junction proteins analysed in the present study were stimulated by the high$\mathrm{fCHO} /$ low-fCP diet in the proximal colon and down-regulated by high fCP in both the segments irrespective of fCHO inclusion. This suggests that high $\mathrm{fCHO}$ are effective in a low-protein background, but that they are unable to interfere with the effects of high fCP on tight junctions.

Apparent changes in the expression of mucosal tight junction proteins could be the result of structural changes such as alterations in mucosal surface area. This can be excluded, because the tight junction proteins examined were differentially regulated (e.g. the abundance of claudin-4 fCHO-dependently increased), electrophysiological parameters were unaffected and total colonic occludin expression (sum of band signals) was not affected by the diets.

Generally, down-regulation of epithelial cell adhesion structures including tight junctions is a hallmark of epithelialto-mesenchymal transition and TGF- $\beta$ is a master regulator of this process ${ }^{(52)}$. Of the cytokines analysed in the present study, the expression of TGF- $\beta$ was most prominently up-regulated $^{(27)}$ and that of tight junction proteins was down-regulated. Although closely linked, the effects of epithelial-to-mesenchymal transition are different from those of classical intestinal inflammation, where the levels of poreforming claudins are up-regulated and those of tightening claudins are down-regulated ${ }^{(34)}$.

\section{Conclusion}

A clear influence of $\mathrm{fCHO}$ and fCP on colon luminal microbial ecology and an increased expression of pro- and anti-inflammatory marker genes in the colonic epithelium have been observed in the same animals that were examined in the present study ${ }^{(28)}$. However, diet-induced changes in the colonic expression of pro- and anti-inflammatory marker genes apparently did not correlate with functional data, as the results of the present study did not demonstrate the dependence of gut barrier on luminal microbial ecology. Interestingly, the expression of tight junction proteins was substantially altered, but it also did not translate into changes in the intestinal barrier function. Collectively, the results of the present study suggest that despite changes in tissue relative concentrations of a number of tight junction proteins, an efficient epithelial barrier is maintained.

We thus propose a previously unrecognised diet-triggered mucosal adaption of proteins known to maintain paracellular barrier function and epithelial homeostasis upon changes in luminal microbial ecology in the large intestine of pigs. Whether the effects observed in the present study would have long-term influence on resistance to infectious challenges requires further studies.

\section{Supplementary material}

To view supplementary material for this article, please visit http://dx.doi.org/10.1017/S0007114513003498 


\section{Acknowledgements}

The authors thank A. Fromm, I. M. Lee and D. Sorgenfrei for their excellent technical assistance and K. Neumann and A. Busjahn for profound support in statistical issues.

The present study received financial support from Evonik Industries (Hanau - Wolfgang, Germany) and the German Research Foundation (DFG) through grant no. SFB852/1 and funding through the Canadian Swine Research and Development Cluster. None of the funders had a role in the design and analysis of the study or in the writing of this article.

The authors' contributions are as follows: J. F. R., R. P., D. G., J. D. S. and A. G. V. K. designed the research; J. F. R., R. P., S. S. Z. and A. G. V. K. conducted the research; J. F. R., R. P. and A. G. V. K. analysed the data; J. F. R., R. P. and A. G. V. K. wrote the paper; J. F. R. had primary responsibility for final content. All the authors read and approved the final version of the manuscript.

None of the authors has any conflicts of interest.

\section{References}

1. De Preter V, Hamer HM, Windey K, et al. (2011) The impact of pre- and/or probiotics on human colonic metabolism: does it affect human health? Mol Nutr Food Res 55, 46-57.

2. Heo JM, Opapeju FO, Pluske JR, et al. (2013) Gastrointestinal health and function in weaned pigs: a review of feeding strategies to control post-weaning diarrhoea without using in-feed antimicrobial compounds. J Anim Physiol Anim Nutr (Berl) 97, 207-237.

3. Kau AL, Ahern PP, Griffin NW, et al. (2011) Human nutrition, the gut microbiome and the immune system. Nature $\mathbf{4 7 4}$, $327-336$.

4. Blaut M \& Clavel T (2007) Metabolic diversity of the intestinal microbiota: implications for health and disease. $J$ Nutr 137, 751-755.

5. Lupton JR (2004) Microbial degradation products influence colon cancer risk: the butyrate controversy. J Nutr 134, 479-482.

6. Ball RO \& Aherne FX (1987) Influence of dietary nutrient density, level of feed intake and weaning age on young pigs. II. Apparent nutrient digestibility and incidence and severity of diarrhea. Can J Anim Sci 67, 1105-1115.

7. Macfarlane S \& Macfarlane GT (2006) Composition and metabolic activities of bacterial biofilms colonizing food residues in the human gut. Appl Environ Microbiol 72, 6204-6211.

8. Russell WR, Gratz SW, Duncan SH, et al. (2011) Highprotein, reduced-carbohydrate weight-loss diets promote metabolite profiles likely to be detrimental to colonic health. Am J Clin Nutr 93, 1062-1072.

9. McGarr SE, Ridlon JM \& Hylemon PB (2005) Diet, anaerobic bacterial metabolism, and colon cancer - a review of the literature. J Clin Gastroenterol 39, 98-109.

10. Maslowski KM, Vieira AT, Ng A, et al. (2009) Regulation of inflammatory responses by gut microbiota and chemoattractant receptor GPR43. Nature 29, 1282-1286.

11. Bordin M, D'Atri F, Guillemot L, et al. (2004) Histone deacetylase inhibitors up-regulate the expression of tight junction proteins. Mol Cancer Res 2, 692-701.

12. Bergann T, Plöger S, Fromm A, et al. (2009) A colonic mineralocorticoid receptor cell model expressing epithelial $\mathrm{Na}^{+}$ channels. Biochem Biophys Res Commun 382, 280-285.
13. Zeissig S, Fromm A, Mankertz J, et al. (2007) Butyrate induces intestinal sodium absorption via Sp3-mediated transcriptional up-regulation of epithelial sodium channels. Gastroenterology 132, 236-248.

14. Amasheh S, Milatz S, Krug SM, et al. (2009) $\mathrm{Na}^{+}$absorption defends from paracellular back-leakage by claudin- 8 upregulation. Biochem Biophys Res Commun 378, 45-50.

15. Capaldo CT \& Nusrat A (2009) Cytokine regulation of tight junctions. Biochim Biophys Acta 1788, 864-871.

16. Turner JR (2009) Intestinal mucosal barrier function in health and disease. Nat Rev Immunol 9, 799-809.

17. Weber CR, Nalle SC, Tretiakova M, et al. (2008) Claudin-1 and claudin-2 expression is elevated in inflammatory bowel disease and may contribute to early neoplastic transformation. Lab Invest 88, 1110-1120.

18. Prasad S, Mingrino R, Kaukinen K, et al. (2005) Inflammatory processes have differential effects on claudins 2, 3 and 4 in colonic epithelial cells. Lab Invest 85, 1139-1162.

19. Elkouby-Naor L \& Ben-Yosef T (2010) Functions of claudin tight junction proteins and their complex interactions in various physiological systems. Int Rev Cell Mol Biol 279, 1-32.

20. Hermes RG, Molist F, Ywazaki M, et al. (2009) Effect of dietary level of protein and fiber on the productive performance and health status of piglets. J Anim Sci 87, 3569-3577.

21. Htoo JK, Araiza BA, Sauer WC, et al. (2007) Effect of dietary protein content on ileal amino acid digestibility, growth performance, and formation of microbial metabolites in ileal and cecal digesta of early-weaned pigs. J Anim Sci 85, 3303-3312.

22. Jeaurond EA, Rademacher M, Pluske JR, et al. (2008) Impact of feeding fermentable proteins and carbohydrates on growth performance, gut health and gastrointestinal function of newly weaned pigs. Can J Anim Sci 88, 271-281.

23. Bikker P, Dirkzwager A, Fledderus J, et al. (2006) The effect of dietary protein and fermentable carbohydrates levels on growth performance and intestinal characteristics in newly weaned piglets. J Anim Sci 84, 3337-3345.

24. Pieper R, Bindelle J, Rossnagel B, et al. (2009) Effect of carbohydrate composition in barley and oat cultivars on microbial ecophysiology and the proliferation of Salmonella enterica in an in vitro model of the porcine gastrointestinal tract. Appl Environ Microbiol 75, 7000-7016.

25. Metzler-Zebeli BU, Hooda S, Pieper R, et al. (2010) Nonstarch polysaccharides modulate bacterial microbiota, pathways for butyrate production, and abundance of pathogenic Escherichia coli in the pig gastrointestinal tract. Appl Environ Microbiol 76, 3692-3701.

26. Heo JM, Kim JC, Hansen CF, et al. (2009) Feeding a diet with decreased protein content reduces indices of protein fermentation and the incidence of postweaning diarrhea in weaned pigs challenged with an enterotoxigenic strain of Escherichia coli. J Anim Sci 87, 2833-2843.

27. Pieper R, Kröger S, Richter JF, et al. (2012) Fermentable fiber ameliorates fermentable protein-induced changes in microbial ecology, but not the mucosal response, in the colon of piglets. J Nutr 142, 661-667.

28. National Research Council (1998) Nutrient Requirements of Swine, 10th revised ed. Washington, DC: National Academy Press.

29. Kreusel KM, Fromm M, Schulzke JD, et al. (1991) $\mathrm{Cl}^{-}$ secretion in epithelial monolayers of mucus-forming human colon cells. Am J Physiol 261, 574-582.

30. Günzel D, Zakrzewski SS, Schmid T, et al. (2012) From TER to trans- and paracellular resistance: lessons from impedance spectroscopy. Ann N Y Acad Sci 1257, 142-151. 
31. Barmeyer C, Amasheh S, Tavalali S, et al. (2004) IL-1beta and TNFalpha regulate sodium absorption in rat distal colon. Biochem Biophys Res Commun 317, 500-507.

32. Günzel D, Stuiver M, Kausalya PJ, et al. (2009) Claudin-10 exists in six alternatively spliced isoforms that exhibit distinct localization and function. J Cell Sci 122, 1507-1151.

33. Rasband WS (1997-2013) ImageJ. Bethesda, MD: US National Institutes of Health. http://imagej.nih.gov/ij/ (accessed January 2011).

34. Krug SM, Amasheh S, Richter JF, et al. (2009) Tricellulin forms a barrier to macromolecules intricellular tight junctions without affecting ion permeability. Mol Biol Cell 20, $3713-3724$

35. von Bonsdorff CH, Fuller SD \& Simons K (1985) Apical and basolateral endocytosis in Madin-Darby canine kidney (MDCK) cells grown on nitrocellulose filters. EMBO $J \mathbf{4}$, 2781-2792.

36. Heyman M, Ducroc R, Desjeux JF, et al. (1982) Horseradish peroxidase transport across adult rabbit jejunum in vitro. Am J Physiol 242, G558-G564.

37. Amasheh S, Meiri N, Gitter AH, et al. (2002) Claudin-2 expression induces cation-selective channels in tight junctions of epithelial cells. J Cell Sci 115, 4969-4976.

38. Yu AS, Enck AH, Lencer WI, et al. (2003) Claudin-8 expression in Madin-Darby canine kidney cells augments the paracellular barrier to cation permeation. $J$ Biol Chem 278, 17350-17359.

39. Barmeyer C, Harren M, Schmitz H, et al. (2004) Mechanisms of diarrhea in the interleukin-2-deficient mouse model of colonic inflammation. Am J Physiol Gastrointest Liver Physiol 286, 244-252.

40. Schumann M, Winter S, Wichner K, et al. (2012) CCR7 deficiency causes diarrhea associated with altered ion transport in colonocytes in the absence of overt colitis. Mucosal Immunol 5, 377-387.
41. Bergann T, Zeissig S, Fromm A, et al. (2009) Glucocorticoids and tumor necrosis factor-alpha synergize to induce absorption by the epithelial sodium channel in the colon. Gastroenterology 136, 933-942.

42. Günzel D \& Fromm M (2012) Claudins and other tight junction proteins. Compr Physiol 2, 1819-1852.

43. Shen L, Weber CR, Raleigh DR, et al. (2011) Tight junction pore and leak pathways: a dynamic duo. Annu Rev Physiol 73, 283-309.

44. Plöger S, Stumpff F, Penner GB, et al. (2012) Microbial butyrate and its role for barrier function in the gastrointestinal tract. Ann N Y Acad Sci 1258, 52-59.

45. Schmitz H, Fromm M, Bentzel CJ, et al. (1999) Tumor necrosis factor-alpha (TNFalpha) regulates the epithelial barrier in the human intestinal cell line HT-29/B6. J Cell Sci 112, $137-146$

46. Turksen K \& Troy TC (2011) Junctions gone bad: claudins and loss of the barrier in cancer. Biochim Biophys Acta 1816, 73-79.

47. Feldman GJ, Mullin JM \& Ryan MP (2005) Occludin: structure, function and regulation. Adv Drug Deliv Rev 57, 883-917.

48. Cummins PM (2012) Occludin: one protein, many forms. Mol Cell Biol 32, 242-250.

49. Blasig IE, Bellmann C, Cording J, et al. (2011) Occludin protein family: oxidative stress and reducing conditions. Antioxid Redox Signal 15, 1195-1219.

50. Raleigh DR, Boe DM, Yu D, et al. (2011) Occludin S408 phosphorylation regulates tight junction protein interactions and barrier function. $J$ Cell Biol 193, 565-582.

51. Bojarski C, Weiske J, Schöneberg T, et al. (2004) The specific fates of tight junction proteins in apoptotic epithelial cells. J Cell Sci 117, 2097-2107.

52. Nieto MA (2011) The ins and outs of the epithelial to mesenchymal transition in health and disease. Annu Rev Cell Dev Biol 27, 347-376. 